\title{
An Update on Promising Diagnostic and Therapeutic Interventions in Epilepsy
}

Leonard LL Yeo*, Jonathan YY Ong, Benjamin R Wakerley, Rahul Rathakrishnan

Division of Neurology, Department of Medicine, National University Hospital, Singapore

\begin{abstract}
There have been many developments in the management of patients with epilepsy ranging from diagnostic modalities to pharmacological and non-pharmacological interventions. This review discusses several advances which the authors believe will have a significant impact on how such patients will be managed in the coming years.

Electroencephalography $[E E G]$ remains the main diagnostic tool in the evaluation of patients with seizure disorders. The novel discovery of high frequency EEG oscillations introduces new concepts of epileptogenicity. Also, techniques that couple EEG with imaging data will be discussed.

The early intervention to abort seizures using a method that is easily administered by paramedic staff in the field has been shown to result in more rapid seizure cessation we elaborate on the pre-hospital management. Epilepsy surgery which has revolutionized the treatment of medically refractory patients is invasive and often resective in nature. We discuss the emerging science of neurostimulation as an alternative and potentially similarly efficacious technique.
\end{abstract}

Keywords: Epilepsy; Therapeutic; Diagnostic; EEG; fMRI; SISCOM; Benzodiazepine

\section{Introduction}

The last decade has seen a significant number of advances in the research of epilepsy, many of which have achieved clinical relevance. Further developments are still in progress, both in the diagnosis and the treatment of patients with epilepsy. This article describes those that are felt to make a significant clinical impact in the decade to come.

\section{Diagnostic Advances}

\section{Functional MRI (fMRI)}

When deciding if a patient is suitable for epilepsy surgery it is important to determine whether removal of a potentially epileptogenic area will have deleterious effects on cortical function, particularly language and memory. In some centers fMRI has now replaced intra-carotid sodium amobarbital [Wada] testing to predict cortical dominance. It works by measuring changes in blood oxygen dependent levels [BOLD] and provides a surrogate of neuronal activity [1-3]. Not only has fMRI been shown to be more accurate, especially in terms of possible verbal and naming deficits compared to Wada testing [4$10]$, but it can also be used to determine cortical function in patients with disrupted brain architecture. Localization of eloquent areas remains important and being able to distinguish between primary and secondary motor areas [11-16] is crucial if the resection zone is within the motor strip. Similarly, visual deficits can be predicted by generating retinotropic maps with fMRI $[17,18]$.

There are however some disadvantages, particularly as fMRI requires the patient to be able to perform certain tasks in order to generate activation maps, which is not always possible in young children or those with cognitive dysfunction. In such cases the Wada test is more useful to determine language dominance. The significance of language maps generated with fMRI also remains uncertain as language centers often extend beyond Broca's and Wernicke's area [1927] and in some cases critical areas remain quiescent. Avoiding aphasia therefore cannot be predicted in all surgical patients [28-31].

\section{Simultaneous electroencephalography and fRMI (EEG-fMRI)}

Accurate identification of the epileptogenic zone is pivotal in determining a successful outcome from epilepsy surgery in patients with intractable seizures. In such cases, scalp or non-invasive EEG monitoring does not provide sufficient accuracy in localization and intracerebral EEG is required. Placement of intracerebral electrodes however presents its own problems. Not only is it invasive and costly, but it only allows a small area of cortex to be monitored and therefore pre-operative assessment with other imaging modalities which augment accurate placement is vital.

Functional magnetic resonance imaging [fMRI] provides a useful non-invasive means of identifying potentially epileptogenic generators in patients with focal epilepsy who may benefit from surgery [32, 33-35]. When fMRI is performed simultaneously with scalp EEG, it enables identification of epileptogenic networks, their boundaries and potentially the location of epileptogenic generators [32-35].

By studying global neuronal activity, fMRI allows detailed analysis of epileptogenic networks in generalized seizures and areas surrounding a focal interictal event beyond that which is normally achieved with standard neurophysiological recordings [36-39]. fMRI is particularly useful in patients with malformations of cortical development [40] and has the potential to determine the effects of epileptogenic lesions on cognitive processes [41]. In some patients focal areas of deactivation are observed in areas contralateral to regions displaying interictal activity, although the significance of this remains uncertain [42]. BOLD signal

${ }^{*}$ Corresponding author: Leonard Yeo, Division of Neurology, National University Hospital. 5 Lower Kent Ridge Road 119074, Singapore, Tel: 65-67724353; Fax: 65-67794112; E-mail: leonardyeoll@gmail.com

Received March 29, 2013; Accepted April 20, 2013; Published April 25, 2013

Citation: Yeo LLL, Ong JYY, Wakerley BR, Rathakrishnan R (2012) An Update on Promising Diagnostic and Therapeutic Interventions in Epilepsy. J Neurol Neurophysiol S2:005 doi:10.4172/2155-9562.S2-005

Copyright: ( 2012 Yeo LLL, et al. This is an open-access article distributed unde the terms of the Creative Commons Attribution License, which permits unrestricted use, distribution, and reproduction in any medium, provided the original author and source are credited. 
is also affected pharmacologically due to changes in cerebral blood flow and therefore may also have a role in the future assessment of antiepileptic drugs [32].

Despite the advantages of being non-invasive and providing information over the whole brain, EEG-fMRI cannot reliably distinguish between irritative and epileptogenic zones, or the effects of seizure propagation, which can be assessed with intracranial electrodes. In addition, the epileptogenic zone is not always identified as was demonstrated in two large studies in which only half of patients with focal seizures exhibited discharges during the 10-60 minute recording $[34,35]$.

\section{Subtraction ictal SPECT co-registered to MRI (SISCOM)}

The epileptogenic zone often resides within the anterior or mesial temporal lobe, and when removed may result in $70 \%$ of patients becoming seizure free. A significant proportion of patients however fail surgery. In some cases this is due to non-diagnostic MRI or inconclusive histology and in others, the occurrence of extra-temporal seizures $[43,44] .20 \%$ of patients with intractable seizures fail initial surgery, although the outcome does improve when repeated $[44,45]$.

The inability of fMRI to identify with certainty all areas of pathological foci has led to the development of more eloquent diagnostic tools. One such method, known as SISCOM [subtraction ictal SPECT co-registered to MRI] combines functional data acquired from single photon emission CT [SPECT] and anatomical detail acquired by MRI. Changes in neuronal activity correlate with cerebral blood flow and can be measured following administration of a radiotracer. Areas of hyperperfusion can therefore be used to identify the epileptogenic focus or if there is seizure propagation, reveal distal sites. By combining this functional data with MRI, SPECT becomes a highly discriminative tool when planning surgery, especially if MRI alone is unable to identify the epileptogenic focus. Sometimes MRI reveals a large lesion, which cannot be fully removed and SISCOM allows a more targeted approach [46]. In cases of initial surgical failure, SISCOM can be used to determine cortical electrode placement to increase accuracy if further surgery is contemplated $[47,48]$.

Several studies indicate that the use of pre-operative SISCOM improves outcome in patients with temporal and extra-temporal disease $[49,50]$. This is particularly apparent when supported by EEG or PET evidence of a localized epileptogenic zone $[51,52]$.

SISCOM is expensive and not indicated in all patients, particularly those with simple cases of hippocampal sclerosis. It can however prove invaluable in more complex cases, especially in patients with cortical dysplasia when the epileptogenic zone may extend SISCOM is beyond the lesion visualized on MRI.

\section{High frequency oscillations}

Fast electroencephalographic [EEG] activity greater than $80 \mathrm{~Hz}$ frequency have been termed high-frequency oscillations [HFOs]. These were originally detected via microelectrodes positioned in the hippocampus, entorhinal cortex and subiculum of patients with mesial temporal lobe epilepsy who were undergoing intracranial EEG as part of pre-surgical evaluations [53-55]. These were noted during wakeful immobility and slow-wave sleep [56]. HFOs recorded from human brains closely resembled ripple oscillations found in nonprimate hippocampi. HFOs in the $80-200 \mathrm{~Hz}$ range are termed 'ripples' and 200-600 Hz 'fast ripples' [57-59].

Physiologically, ripples represent summated inhibitory post- synaptic potentials arising from presumed interneurons and are believed to play a role in the imprinting of episodic memory that occurs as a result of the synchronization of neuronal activity [57].

Pathological HFOs are thought to represent the field potentials of population spikes from clusters of abnormal synchronous burst-firing neurons within epileptogenic tissue [60]. From the identification of its pathological role a decade ago, the body of knowledge surrounding HFOs in patients with epilepsy has grown significantly as electrophysiological equipment capable of recording at these high frequencies has become more readily available [61-69]. Furthermore, HFOs have been observed in intracranial EEG recorded using conventional macroelectrodes which obviates the need for special amplification and analytical tools that are required when studying microelectrode recordings [70-73]. In patients with focal epilepsy, generators of HFO may be recorded from regions as small as $1 \mathrm{~mm}^{3}$ using microelectrodes and in the range of 1 or a few $\mathrm{cm}^{3}$ using macroelectrodes [53-55, 74-76]. However, it does not appear that the nature of the HFOs recorded by the different electrode is entirely similar. Pathological HFOs were initially believed to be restricted to the fast ripple frequency spectra but this has since been acknowledged to be an oversimplification [77]. Fast ripples can be recorded from normal neocortex and ripples have been found in epileptic dentate gyrus where physiological HFOs do not occur [78].

Approximately one third of patients with focal epilepsy will prove to be medically refractory [78]. Intuitively, the removal of the epileptogenic tissue in these patients will potentially have a curative result. Invasive methods are used to delineate these areas in great detail $[79,80]$. Yet, removal of the seizure onset zone (SOZ) does not always equate to seizure freedom [81-84].

Studies have shown that HFOs may be markers of epileptogenicity [72]. Irrespective of the underlying epileptogenic lesion and its boundaries, HFOs appear to be closely associated with the SOZ [85]. Whilst the majority of the HFOs occur within the SOZ as identified using standard methods [intracranial EEG], they have also been observed in adjacent tissue $[86,87]$. Failure to remove these HFO laden areas which are outside the $\mathrm{SOZ}$ has been associated with poorer surgical outcomes [88]. It is a more robust marker than traditional EEG spikes, following the discovery that reductions in anticonvulsant medication results in an increase in the number of HFOs recorded [89]. The combination of the two electrographical features indicates that neurons in that particular vicinity are capable of generating hypersynchronous action potentials and are potentially highly epileptogenic.

More recently, interictal HFOs have been successfully recorded using standard scalp EEG electrodes after careful separation from EMG artifact $[90,91]$. This holds promising future applications particularly as non-invasive biomarkers for epileptogenic brain regions [61-63,65,90]. At present further studies are required to be able to definitively differentiate pathological and physiological HFOs. Automated detection systems are currently being designed to relieve the laborious efforts undertaken to manually mark HFOs which currently can only be performed on several minutes of carefully selected EEG epochs [92].

\section{Continuous Electroencephalography (CEEG)}

Continuous EEG monitoring is now being advocated in the intensive care, particularly patients with underlying seizure disorders. Seizures occur commonly in structural brain insults and encephalopathic states [93]. Between 11-55\% of patients in the neurological intensive care unit may experience seizures. [94]. More than $90 \%$ of these are nonconvulsive in nature and are associated 
with higher mortality and morbidity rates [94,95]. EEG has the dual advantage of providing excellent temporal resolution [up to $2 \mathrm{~ms}$ ] and sufficient spatial resolution that allows brain abnormalities to be regionalized [94]. With the application of Fast Fourier Transformation digital EEG signals from prolonged recordings can be condensed into user-friendly graphical quantitative trends that potentially may be used by non-electroencephalographers. These commercially available modes of display include compressed spectral array, density spectral array, bispectral index and power values [96-102].

Recent developments involve the use of EEG outside the setting of seizure disorder. Research is ongoing in the ability of EEG to detect neuronal dysfunction that occurs as a result of disturbances of brain perfusion. EEG detects changes in cerebral perfusion prior to the point of irreversible damage and this provides a window of opportunity to perform further investigations to corroborate the findings or to very closely monitor the patient clinically and institute changes in management [103]. Increasing research has taken place in the use of CEEG in patients with subarachnoid hemorrhage, a major complication of which is delayed cerebral ischemia [DCI]. This is a clinical phenomenon of vasospasm-related hypoperfusion and occurs in $22-40 \%$ of patients, resulting in morbidity and mortality rates of up to $30 \%$ [104-106].

Alterations in CEEG can precede clinical change by more than 24 hours. In recent studies, a single measurable CEEG parameter improved the ability to predict the progress of patients with SAH a day in advance by detecting EEG changes at the pre-clinical stage [107]. This ultra-early detection suggests that in a proportion of patients, the therapeutic window of intervention to prevent permanent neurological damage may extend beyond 24 hours.

\section{Therapeutic Advances}

\section{Pre-hospital management of seizures}

The management of epilepsy has continued to evolve in the last two years beyond the use of anti-epileptic medication, which continues to be the mainstay of treatment. Paradigm shifts in the approach to prehospital treatment of continuous seizures have gained attention with recent evidence suggesting that intramuscular [IM] benzodiazepine administration may be equally effective as the intravenous [IV] route. This review serves to highlight these recent developments in this everchanging field.

Early termination of prolonged seizures and status epilepticus using IV benzodiazepines has been shown to improve patient outcomes. The Pre-hospital Treatment of Status Epilepticus trial compared intravenously administered diazepam, lorazepam, and placebo given by paramedics to treat subjects with prolonged convulsive seizures and established that benzodiazepines were an effective pre-hospital treatment for seizure control as compared with placebo [108].

A meta-analysis of several small trials studying the use of nonintravenous midazolam in the hospital setting compared favorably with intravenous diazepam in the treatment of status epilepticus [109]. Although intravenous lorazepam is the preferred benzodiazepine for aborting seizures in the emergency department, practical issues such as obtaining rapid IV access may preclude its use in the field. Furthermore, lorazepam has a short shelf life with poor stability when it is not refrigerated [110]. Pharmacodynamic and pharmacokinetic studies have shown that IM midazolam is rapidly absorbed. For these reasons, some emergency medical services have advocated the use of
IM benzodiazepines such as midazolam to achieve a faster and more consistent administration with the aim of rapid cessation of seizure activity [111].

The recently concluded Rapid Anticonvulsant Medication Prior to Arrival Trial [RAMPART] established that intramuscular midazolam is safe and as efficacious as intravenous lorazepam for pre-hospital seizure abortion in children and adults [112]. This was a randomized, double blind, phase 3, non-inferiority clinical trial that involved 1023 participants. Adults and children with an estimated body weight of more than $40 \mathrm{~kg}$ received either $10 \mathrm{mg}$ of intramuscular midazolam followed by intravenous placebo, or intramuscular placebo followed by $4 \mathrm{mg}$ of intravenous lorazepam. In children with an estimated weight of 13 to $40 \mathrm{~kg}$, the active treatment was $5 \mathrm{mg}$ of intramuscular midazolam or $2 \mathrm{mg}$ of intravenous lorazepam. The intramuscular medications were administered via a pre-manufactured auto-injector, which reduced delays in drug administration when compared to the intravenous route (1.2 versus 4.8 minutes respectively). $73.4 \%$ of patients who received IM midazolam were seizure-free on arrival at the Emergency Room compared to $63.4 \%$ who received IV lorazepam (95\% CI 4.0 to $16.1, \mathrm{p}=0.001$ for non-inferiority and superiority). Interestingly, the proportion of subjects admitted was significant lower and the proportion discharged from the emergency department was significantly higher in the IM group than in the IV group. However, for patients who required hospital admission, the length of stay did not differ significantly between the two groups. This study provides initial evidence that the pre-hospital administration of IM midazolam by paramedics to abort seizures is an effective, practical and safe alternative to the IV route. Successful early termination of seizures in the field improves patient outcomes and may reduce hospital admission rates.

\section{Neurostimulation techniques}

Patients who are medically refractory to multiple trials of antiepileptic medication should be assessed for their suitability to undergo epilepsy surgery. In the appropriately selected patients, this may be a curative intervention whilst in other cases, palliative insofar as reducing the number of seizures whilst not being able to achieve complete seizure freedom [113].

However, not all patients will be surgical candidates. In some, epileptiform foci may be multifocal, bilateral, or located in a highly eloquent and functionally important region of the brain. For such patients, novel procedures such as neurostimulation and highly localized ablative therapy are emerging as viable therapeutic strategies.

Vagal Nerve stimulation (VNS): Although the precise mechanism of action is unknown, it has been shown from various studies dating back to the 1930s that stimulation of the vagus nerve was able to modulate EEG changes. Subsequent development in this field has resulted in an FDA-approved scheduled closed loop system of continuous high frequency stimulation which is believed to cause desynchronisation of EEG, changes in sleep architecture and the ability to suppress interictal epileptiform discharges [114-116]. It is also possible that the stimulation of the vagus nerve is itself inhibitory causing a rise in of gamma-aminobutyric acid [GABA] levels [114]. It has proven to be efficacious in seizure reduction of partial and to a lesser extent, generalized epilepsies, with $40 \%$ of patients enjoying a $50 \%$ reduction in seizure frequency [117-122].

From a practical point of view, the VNS device is similar to a cardiac pacemaker in that it involves the subcutaneous or submuscular implantation of a generator which is then attached to leads that wrap around the left vagus nerve in the neck [120]. A craniotomy is not 
required. Due to the lateralized functions of the vagal system, the right vagus nerve is avoided in order to minimize the potential cardio-vagal effects [114]. In experienced hands, the effects of this technique are minimal, usually associated with a mild cough on stimulation and hoarseness of voice.

Thalamic stimulation: The thalamus has long been thought of as a central relay station in the brain and with its close connections to the mesial temporal structures via the thalamocortical and mamillothalamic tracts, may be a potential target in the modulation of epileptic activity $[123,124]$. Indeed, this has been studied extensively in animals. Recently, a large blinded controlled study was undertaken which corroborates the results of animal studies [125-128]. The SANTE trial reported a $38 \%$ seizure reduction in patients who underwent active stimulation. At 2 years $60 \%$ of patients had their seizure frequency reduced by half, with $9 \%$ even attaining seizure freedom [129].

Hippocampal stimulation: Another intuitively attractive target would be the hippocampus which is intricately involved in seizure propagation, particularly in the temporal lobe epilepsies. Although small scale animal studies have been performed, they are preliminary and larger scale and longer term clinical trials assessing efficacy and safety have yet to be performed. Its usage should be reserved until controlled clinical studies of stimulation of the mesial temporal structures are performed $[130,131]$.

Responsive neurostimulation: A routine pre-surgical assessment prior to resective epilepsy surgery involves the implantation of electrodes at the region of interest in the brain to further delineate the epileptogenic focus that is recorded from the scalp. Further to this, electrical stimulation via these electrodes is occasionally applied in awake patients to map the eloquent areas of the brain. It is also possible to identify the sites that may trigger electrographical after-discharges when stimulated. These have the potential to evolve into frank ictal activity.

Subsequently it was discovered that delivery of a short burst of $50 \mathrm{~Hz}$ stimulation via the same electrodes into these regions could ameliorate the occurrence of these after-discharges, hence potentially terminating this electrical precursor to a full-blown ictal event $[132,133]$. The Responsive Neurostimulation System [RNS] has been evaluated in multi-center controlled clinical trials as an adjunctive modality for use in adults with refractory partial seizures [134]. Leads are connected to a neurostimulation device [implanted in the skull] that detects electrographic seizures with electrocorticography. Patient specific electrographical ictal patterns are identified. Using this data, the system is therefore able to detect aberrant electrographical activity and subsequently deliver high frequency stimulation into the epileptopgenic tissue in order to abort the discharges. This modality is especially suitable in the treatment of epilepsy with seizure onset in eloquent areas which are not resectable in an operation, as the stimuli do not disrupt cortical function [135].

\section{Stereoelectroencephalography aided thermocoagulation}

Using the same platform of pre-surgical electrode implantation phase of the assessment of patients with medically refractory epilepsy, stereoencephalography guided thermocoagulation is a novel method that is being studied $[136,137]$. Once the responsible foci of epileptogenesis have been identified, these areas are ablated using a radiofrequency generator. This allows the targeted and individualized removal of tissue or at least a disconnection of the epileptic network to prevent seizure propagation. This modality appears to be safe and had demonstrated a $50 \%$ seizure reduction rate in $48.7 \%$ of patient who underwent this procedure [138]. Whilst less invasive than conventional surgery, it has not been proven to be as efficacious $[139,141]$. However this procedure is comparable to other palliative therapeutic procedures $[142,143]$. This technique does not preclude the patient from being considered for epilepsy surgery later on if this is deemed appropriate.

\section{Magnetic resonance-guided laser ablation for epilepsy}

In patients who have a lesion visible on MRI that is clearly the focus of epileptogenic activity without the need to undergo invasive monitoring, an MRI-guided ablative laser resection may be a therapeutic option. Magnetic Resonance-guided laser ablation has been used for tumor resection, and even with limited imaging feedback has been proven to be very safe [144-146]. Recently, the FDA cleared the first MRI-guided laser interstitial thermal therapy allowing for real-time thermal monitoring and feedback over the amount of energy delivered via the laser. Laser energy could be delivered while observing the damage calculated from real-time thermal images, greatly increasing the precision. In a limited study of 5 patients, all remained seizure-free at least 2 to 13 months post-procedure. All subjects in the study had deeply seated epileptogenic zones and would have required transcortical corridors through normal brain [or extensive dissection of it] to complete their removal. This shows that guided laser resection may reduce morbidity in patients who required re-operations for surgical failure require extensive dissection of scarred brain from the dura, or have multifocal epilepsy that would require more than one craniotomy to affect a cure $[147,148]$.

\section{References}

1. Ives JR, Warach S, Schmitt F, Edelman RR, Schomer DL (1993) Monitoring the patient's EEG during echo planar MRI. Electroencephalogr Clin Neurophysio 87: $417-420$

2. Ogawa S, Tank DW, Menon R, Ellermann JM, Kim SG, et al. (1992) Intrinsic signal changes accompanying sensory stimulation: functional brain mapping with magnetic resonance imaging. Proc Natl Acad Sci U S A 89: 5951-5955.

3. Logothetis NK, Wandell BA (2004) Interpreting the BOLD signal. Annu Rev Physiol 66: 735-769.

4. Benson RR, FitzGerald DB, LeSueur LL, Kennedy DN, Kwong KK, et al. (1999) Language dominance determined by whole brain functional MRI in patients with brain lesions. Neurology 52: 798-809.

5. Lehéricy S, Cohen L, Bazin B, Samson S, Giacomini E, et al. (2000) Functiona MR evaluation of temporal and frontal language dominance compared with the Wada test. Neurology 54: 1625-1633.

6. Binder JR, Swanson SJ, Hammeke TA, Morris GL, Mueller WM, et al. (1996) Determination of language dominance using functional MRI: a comparison with the Wada test. Neurology 46: 978-984.

7. Benke T, Köylü B, Visani P, Karner E, Brenneis C, et al. (2006) Language lateralization in temporal lobe epilepsy: a comparison between $\mathrm{fMRI}$ and the Wada Test. Epilepsia 47: 1308-1319.

8. Szaflarski JP, Holland SK, Jacola LM, Lindsell C, Privitera MD, et al. (2008) Comprehensive presurgical functional MRI language evaluation in adult patients with epilepsy. Epilepsy Behav 12: 74-83.

9. Arora J, Pugh K, Westerveld M, Spencer S, Spencer DD, et al. (2009) Language lateralization in epilepsy patients: fMRI validated with the Wada procedure. Epilepsia 50: 2225-2241.

10. Suarez RO, Whalen S, Nelson AP, Tie Y, Meadows ME, et al. (2009) Thresholdindependent functional MRI determination of language dominance: a validation study against clinical gold standards. Epilepsy Behav 16: 288-297.

11. Mueller WM, Yetkin FZ, Hammeke TA, Morris GL 3rd, Swanson SJ, et al. (1996) Functional magnetic resonance imaging mapping of the motor cortex in patients with cerebral tumors. Neurosurgery 39: 515-520.

12. Pujol J, Conesa G, Deus J, López-Obarrio L, Isamat F, et al. (1998) Clinica application of functional magnetic resonance imaging in presurgical identification of the central sulcus. J Neurosurg 88: 863-869. 
Citation: Yeo LLL, Ong JYY, Wakerley BR, Rathakrishnan R (2012) An Update on Promising Diagnostic and Therapeutic Interventions in Epilepsy. J Neurol Neurophysiol S2:005 doi:10.4172/2155-9562.S2-005

13. Achten E, Jackson GD, Cameron JA, Abbott DF, Stella DL, et al. (1999) Presurgical evaluation of the motor hand area with functional MR imaging in patients with tumors and dysplastic lesions. Radiology 210: 529-538.

14. Håberg A, Kvistad KA, Unsgård G, Haraldseth O (2004) Preoperative blood oxygen level-dependent functional magnetic resonance imaging in patients with primary brain tumors: clinical application and outcome. Neurosurgery 54: 902-914.

15. Majos A, Tybor K, StefaÅ,czyk L, GÃ ${ }^{3}$ raj B (2005) Cortical mapping by functional magnetic resonance imaging in patients with brain tumors. Eur Radiol 15: 1148-1158.

16. De Tiège X, Connelly A, Liégeois F, Harkness W, Clark CA, et al. (2009) Influence of motor functional magnetic resonance imaging on the surgical management of children and adolescents with symptomatic focal epilepsy. Neurosurgery 64: 856-864

17. Sereno MI, Dale AM, Reppas JB, Kwong KK, Belliveau JW, et al. (1995) Borders of multiple visual areas in humans revealed by functional magnetic resonance imaging. Science 268: 889-893.

18. DeYoe EA, Carman GJ, Bandettini P, Glickman S, Wieser J, et al. (1996) Mapping striate and extrastriate visual areas in human cerebral cortex. Proc Natl Acad Sci U S A 93: 2382-2386.

19. Damasio H, Grabowski TJ, Tranel D, Hichwa RD, Damasio AR (1996) A neura basis for lexical retrieval. Nature 380: 499-505.

20. Binder JR, Frost JA, Hammeke TA, Cox RW, Rao SM, et al. (1997) Human brain language areas identified by functional magnetic resonance imaging. $J$ Neurosci 17: 353-362.

21. Grabowski TJ, Damasio AR (2000) Investigating language with functional neuroimaging.In: Toga AW, Mazziotta JC, editors. Brain mapping: the systems. San Diego, CA: Academic Press: 425-461.

22. Démonet JF, Thierry G, Cardebat D (2005) Renewal of the neurophysiology of language: functional neuroimaging. Physiol Rev 85: 49-95.

23. Dronkers NF, Wilkins DP, Van Valin RD Jr, Redfern BB, Jaeger JJ (2004) Lesion analysis of the brain areas involved in language comprehension. Cognition 92: 145-177.

24. Indefrey P, Levelt WJ (2004) The spatial and temporal signatures of word production components. Cognition 92: 101-144.

25. Awad M, Warren JE, Scott SK, Turkheimer FE, Wise RJ (2007) A common system for the comprehension and production of narrative speech. J Neurosci 27: 11455-11464.

26. Patterson K, Nestor PJ, Rogers TT (2007) Where do you know what you know? The representation of semantic knowledge in the human brain. Nat Rev Neurosci 8: 976-987.

27. Binder JR, Desai R, Conant LL, Graves WW (2009) Where is the semantic system? A critical review and meta-analysis of 120 functional neuroimaging studies. Cereb. Cortex 19: 2767-2796.

28. Ojemann G, Ojemann J, Lettich E, Berger M (1989) Cortical language localization in left, dominant hemisphere. An electrical stimulation mapping investigation in 117 patients. J Neurosurg 71: 316-326.

29. Seghier ML, Lazeyras F, Pegna AJ, Annoni JM, Zimine I, et al. (2004) Variability of fMRI activation during a phonological and semantic language task in healthy subjects. Hum Brain Mapp 23: 140-155.

30. Lazar RM, Antoniello D (2008) Variability in recovery from aphasia. Curr Neuro Neurosci Rep 8: 497-502.

31. Wada J, Rasmussen T (2007) Intracarotid injection of sodium amytal for the lateralization of cerebral speech dominance. 1960. J Neurosurg 106: 11171133.

32. Laufs H, Duncan JS (2007) Electroencephalography/functional MRI in human epilepsy: what it currently can and cannot do. Curr Opin Neurol 20: 417-423.

33. Hufnagel A, Dümpelmann M, Zentner J, Schijns O, Elger CE (2000) Clinical relevance of quantified intracranial interictal spike activity in presurgical evaluation of epilepsy. Epilepsia 41: 467-478.

34. Jirsch JD, Urrestarazu E, LeVan P, Olivier A, Dubeau F, et al. (2006) Highfrequency oscillations during human focal seizures. Brain 129: 1593-1608.

35. Ochi A, Otsubo H, Donner EJ, Elliott I, Iwata R, et al. (2007) Dynamic changes of ictal high-frequency oscillations in neocortical epilepsy: using multiple band frequency analysis. Epilepsia 48: 286-296.

36. Hamandi K, Salek-Haddadi A, Laufs H, Liston A, Friston K, et al. (2006) EEGfMRI of idiopathic and secondarily generalized epilepsies. Neuroimage 31 1700-1710.

37. Archer JS, Abbott DF, Waites AB, Jackson GD (2003) fMRI "deactivation" of the posterior cingulate during generalized spike and wave. Neuroimage 20: 1915-1922.

38. Kobayashi E, Bagshaw AP, Bénar CG, Aghakhani $Y$, Andermann F, et al (2006) Temporal and extratemporal BOLD responses to temporal lobe interictal spikes. Epilepsia 47: 343-354.

39. Laufs H, Hamandi K, Salek-Haddadi A, Kleinschmidt AK, Duncan JS, et al (2007) Temporal lobe interictal epileptic discharges affect cerebral activity in "default mode" brain regions. Hum Brain Mapp 28: 1023-1032.

40. Barkovich AJ, Kuzniecky RI, Jackson GD, Guerrini R, Dobyns WB (2001) Classification system for malformations of cortical development: update 2001 Neurology 57: 2168-2178.

41. Kirschstein T, Fernández G, Grunwald T, Pezer N, Urbach H, et al. (2003) Heterotopias, cortical dysplasias and glioneural tumors participate in cognitive processing in patients with temporal lobe epilepsy. Neurosci Lett 338: 237-241.

42. Rathakrishnan R, Moeller F, Levan P, Dubeau F, Gotman J (2010) BOLD signal changes preceding negative responses in EEG-fMRI in patients with focal epilepsy. Epilepsia 51: 1837-1845.

43. Mosewich RK, So EL, O'Brien TJ, Cascino GD, Sharbrough FW, et al. (2000) Factors predictive of the outcome of frontal lobe epilepsy surgery. Epilepsia 41: 843-849.

44. Radhakrishnan K, So EL, Silbert PL, Jack CR Jr, Cascino GD, et al. (1998) Predictors of outcome of anterior temporal lobectomy for intractable epilepsy: a multivariate study. Neurology 51: 465-471.

45. Awad IA, Nayel MH (1992) Epilepsy surgery: introduction and overview. Clin Neurosurg 38: 493-513.

46. Cascino GD, Buchhalter JR, Sirven JI, So EL, Drazkowski JF, et al. (2004) Peri-ictal SPECT and surgical treatment for intractable epilepsy related to schizencephaly. Neurology 63: 2426-2428.

47. Wetjen NM, Cascino GD, Fessler AJ, So EL, Buchhalter JR, et al. (2006) Subtraction ictal single-photon emission computed tomography coregistered to magnetic resonance imaging in evaluating the need for repeated epilepsy surgery. J Neurosurg 105: 71-76.

48. Ahnlide JA, Rosén I, Lindén-Mickelsson Tech P, Källén K (2007) Does SISCOM contribute to favorable seizure outcome after epilepsy surgery? Epilepsia 48 : 579-588.

49. O'Brien TJ, So EL, Mullan BP, Cascino GD, Hauser MF, et al. (2000) Subtraction peri-ictal SPECT is predictive of extratemporal epilepsy surgery outcome. Neurology 55: 1668-1677.

50. O'Brien TJ, So EL, Cascino GD, Hauser MF, Marsh WR, et al. (2004) Subtraction SPECT coregistered to MRI in focal malformations of cortical development localization of the epileptogenic zone in epilepsy surgery candidates. Epilepsia 45: 367-376.

51. O'Brien TJ, O'Connor MK, Mullan BP, Brinkmann BH, Hanson D, et al. (1998) Subtraction ictal SPET co-registered to MRI in partial epilepsy: description and technical validation of the method with phantom and patient studies. Nucl Med Commun 19: 31-45.

52. Matsuda H, Matsuda K, Nakamura F, Kameyama S, Masuda H, et al. (2009) Contribution of subtraction ictal SPECT coregistered to MRI to epilepsy surgery: a multicenter study. Ann Nucl Med 23: 283-291.

53. Bragin A, Engel J Jr, Wilson CL, Fried I, Mathern GW (1999) Hippocampal and entorhinal cortex high-frequency oscillations $(100--500 \mathrm{~Hz})$ in human epileptic brain and in kainic acid--treated rats with chronic seizures. Epilepsia 40: 127137

54. Bragin A, Engel J Jr, Wilson CL, Vizentin E, Mathern GW (1999) Electrophysiologic analysis of a chronic seizure model after unilatera hippocampal KA injection. Epilepsia 40: 1210-1221.

55. Staba RJ, Wilson CL, Bragin A, Fried I, Engel J Jr (2002) Quantitative analysis of high-frequency oscillations $(80-500 \mathrm{~Hz})$ recorded in human epileptic hippocampus and entorhinal cortex. J Neurophysiol 88: 1743-1752. 
Citation: Yeo LLL, Ong JYY, Wakerley BR, Rathakrishnan R (2012) An Update on Promising Diagnostic and Therapeutic Interventions in Epilepsy. J Neurol Neurophysiol S2:005 doi:10.4172/2155-9562.S2-005

56. Chrobak JJ, Buzsáki G (1996) High-frequency oscillations in the output networks of the hippocampal-entorhinal axis of the freely behaving rat. $J$ Neurosci 16: 3056-3066.

57. Buzsaki G (2006) Rhythms of the Brain. New York, NY: Oxford University Press.

58. Buzsáki G, Horváth Z, Urioste R, Hetke J, Wise K (1992) High-frequency network oscillation in the hippocampus. Science 256: 1025-1027.

59. Suzuki SS, Smith GK (1987) Spontaneous EEG spikes in the normal hippocampus. I. Behavioral correlates, laminar profiles and bilateral synchrony. Electroencephalogr Clin Neurophysiol 67: 348-359.

60. Bragin A, Wilson CL, Staba RJ, Reddick M, Fried I, et al. (2002) Interictal highfrequency oscillations $(80-500 \mathrm{~Hz})$ in the human epileptic brain: entorhinal cortex. Ann Neurol 52: 407-415.

61. Kobayashi K, Watanabe Y, Inoue T, Oka M, Yoshinaga H, et al. (2010) Scalprecorded high-frequency oscillations in childhood sleep-induced electrical status epilepticus. Epilepsia 51: 2190-2194.

62. Willoughby JO, Fitzgibbon SP, Pope KJ, Mackenzie L, Medvedev AV, et al (2003) Persistent abnormality detected in the non-ictal electroencephalogram in primary generalised epilepsy. J Neurol Neurosurg Psychiatry 74: 51-55.

63. Wu JY, Koh S, Sankar R, Mathern GW (2008) Paroxysmal fast activity: an interictal scalp EEG marker of epileptogenesis in children. Epilepsy Res 82: 99-106.

64. Yamazaki M, Chan D, Tovar-Spinoza Z, Go C, Imai K, et al. (2009) Interictal epileptogenic fast oscillations on neonatal and infantile EEGs in hemimegalencephaly. Epilepsy Res 83: 198-206.

65. Kobayashi K, Oka M, Akiyama T, Inoue T, Abiru K, et al. (2004) Very fast rhythmic activity on scalp EEG associated with epileptic spasms. Epilepsia 45: 488-496

66. Inoue T, Kobayashi K, Oka M, Yoshinaga H, Ohtsuka Y (2008) Spectral characteristics of EEG gamma rhythms associated with epileptic spasms. Brain Dev 30: 321-328.

67. Traub RD, Pais I, Bibbig A, Lebeau FE, Buhl EH, et al. (2005) Transient depression of excitatory synapses on interneurons contributes to epileptiform bursts during gamma oscillations in the mouse hippocampal slice. J Neurophysiol 94: 1225-1235

68. Köhling $R$, Vreugdenhil M, Bracci $E$, Jefferys JG (2000) Ictal epileptiform activity is facilitated by hippocampal GABAA receptor-mediated oscillations. J Neurosci 20: 6820-6829.

69. Khazipov R, Holmes GL (2003) Synchronization of kainate-induced epileptic activity via GABAergic inhibition in the superfused rat hippocampus in vivo. $J$ Neurosci 23: 5337-5341.

70. Crépon B, Navarro V, Hasboun D, Clemenceau S, Martinerie J, et al. (2010) Mapping interictal oscillations greater than $200 \mathrm{~Hz}$ recorded with intracranial macroelectrodes in human epilepsy. Brain 133: 33-45.

71. Urrestarazu E, Chander R, Dubeau F, Gotman J (2007) Interictal high-frequency oscillations $(100-500 \mathrm{~Hz})$ in the intracerebral EEG of epileptic patients. Brain 130: $2354-2366$

72. Jacobs J, LeVan P, Chander R, Hall J, Dubeau F, et al. (2008) Interictal highfrequency oscillations $(80-500 \mathrm{~Hz})$ are an indicator of seizure onset areas independent of spikes in the human epileptic brain. Epilepsia 49: 1893-1907.

73. Worrell GA, Gardner AB, Stead SM, Hu S, Goerss S, et al. (2008) Highfrequency oscillations in human temporal lobe: simultaneous microwire and clinical macroelectrode recordings. Brain 131: 928-937.

74. Staba RJ, Wilson CL, Bragin A, Jhung D, Fried I, et al. (2004) High-frequency oscillations recorded in human medial temporal lobe during sleep. Ann Neurol 56: $108-115$.

75. Bragin A, Engel J Jr, Wilson CL, Fried I, Buzsáki G (1999) High-frequency oscillations in human brain. Hippocampus 9: 137-142.

76. Urrestarazu E, Jirsch JD, LeVan P, Hall J, Avoli M, et al. (2006) High-frequency intracerebral EEG activity $(100-500 \mathrm{~Hz})$ following interictal spikes. Epilepsia 47: $1465-1476$

77. Engel J Jr, Bragin A, Staba R, Mody I (2009) High-frequency oscillations: what is normal and what is not? Epilepsia 50: $598-604$.
78. Schuele SU, Lüders HO (2008) Intractable epilepsy: management and therapeutic alternatives. Lancet Neurol 7: 514-524.

79. Diehl B, Lüders HO (2000) Temporal lobe epilepsy: when are invasive recordings needed? Epilepsia 41 Suppl 3: S61-74.

80. Rosenow F, Lüders H (2001) Presurgical evaluation of epilepsy. Brain 124 1683-1700.

81. Boling W, Aghakhani Y, Andermann F, Sziklas V, Olivier A (2009) Surgica treatment of independent bitemporal lobe epilepsy defined by invasive recordings. J Neurol Neurosurg Psychiatry 80: 533-538.

82. Prasad A, Pacia SV, Vazquez B, Doyle WK, Devinsky O (2003) Extent of icta origin in mesial temporal sclerosis patients monitored with subdural intracranial electrodes predicts outcome. J Clin Neurophysiol 20: 243-248.

83. Bautista RE, Cobbs MA, Spencer DD, Spencer SS (1999) Prediction of surgica outcome by interictal epileptiform abnormalities during intracranial EEG monitoring in patients with extrahippocampal seizures. Epilepsia 40: 880-890.

84. Hufnagel A, Dümpelmann M, Zentner J, Schijns O, Elger CE (2000) Clinical relevance of quantified intracranial interictal spike activity in presurgical evaluation of epilepsy. Epilepsia 41: 467-478.

85. Jacobs J, Levan P, Châtillon CE, Olivier A, Dubeau F, et al. (2009) High frequency oscillations in intracranial EEGs mark epileptogenicity rather than lesion type. Brain 132: 1022-1037

86. Jirsch JD, Urrestarazu E, LeVan P, Olivier A, Dubeau F, et al. (2006) Highfrequency oscillations during human focal seizures. Brain 129: 1593-1608.

87. Ochi A, Otsubo H, Donner EJ, Elliott I, Iwata R, et al. (2007) Dynamic changes of ictal high-frequency oscillations in neocortical epilepsy: using multiple band frequency analysis. Epilepsia 48: 286-296.

88. Jacobs J, Zijlmans M, Zelmann R, Chatillon CE, Hall J, et al. (2010) Highfrequency electroencephalographic oscillations correlate with outcome of epilepsy surgery. Ann Neurol 67: 209-220.

89. Zijlmans M, Jacobs J, Zelmann R, Dubeau F, Gotman J (2009) High-frequency oscillations mirror disease activity in patients with epilepsy. Neurology 72: 979 986

90. Andrade-Valenca LP, Dubeau F, Mari F, Zelmann R, Gotman J (2011) Interictal scalp fast oscillations as a marker of the seizure onset zone. Neurology 77 524-531.

91. Herrmann CS, Fründ I, Lenz D (2010) Human gamma-band activity: a review on cognitive and behavioral correlates and network models. Neurosci Biobehav Rev 34: 981-992.

92. von Ellenrieder N, Andrade-Valença LP, Dubeau F, Gotman J (2012) Automatic detection of fast oscillations $(40-200 \mathrm{~Hz})$ in scalp EEG recordings. Clin Neurophysiol 123: 670-680.

93. Young GB, Doig GS (2005) Continuous EEG monitoring in comatose intensive care patients: epileptiform activity in etiologically distinct groups. Neurocrit Care 2: $5-10$.

94. Scheuer ML (2002) Continuous EEG monitoring in the intensive care unit Epilepsia 43 Suppl 3: 114-127.

95. Jordan KG (2004) Emergency EEG and continuous EEG monitoring in acute ischemic stroke. J Clin Neurophysiol 21: 341-352.

96. Bickford RG, Fleming N, Billinger T (1971) Compression of EEG data. Trans Am Neurol Assoc 96: 118-122.

97. Alster J, Pratt H, Feinsod M (1993) Density spectral array, evoked potentials, and temperature rhythms in the evaluation and prognosis of the comatose patient. Brain Inj 7: 191-208.

98. Cant BR, Shaw NA (1984) Monitoring by compressed spectral array in prolonged coma. Neurology 34: 35-39.

99. Mondello E, Panasiti R, Siliotti R, Floridia D, David A, et al. (2002) BIS and Ramsay score in critically ill patient: what future? Minerva Anestesiol 68: 37-43

100. Gilbert TT, Wagner MR, Halukurike V, Paz HL, Garland A (2001) Use of bispectral electroencephalogram monitoring to assess neurologic status in unsedated, critically ill patients. Crit Care Med 29: 1996-2000.

101.Shah AK, Agarwal R, Carhuapoma JR, Loeb JA (2006) Compressed EEG pattern analysis for critically ill neurological-neurosurgical patients. Neurocrit Care 5: 124-133. 
Citation: Yeo LLL, Ong JYY, Wakerley BR, Rathakrishnan R (2012) An Update on Promising Diagnostic and Therapeutic Interventions in Epilepsy. J Neurol Neurophysiol S2:005 doi:10.4172/2155-9562.S2-005

102. Rathakrishnan R, Gotman J, Dubeau F, Angle M (2011) Using continuous electroencephalography in the management of delayed cerebral ischemia following subarachnoid hemorrhage. Neurocrit Care 14: 152-161.

103. Scheuer ML, Wilson SB (2004) Data analysis for continuous EEG monitoring in the ICU: seeing the forest and the trees. J Clin Neurophysiol 21: 353-378.

104. Rigamonti A, Ackery A, Baker AJ (2008) Transcranial Doppler monitoring in subarachnoid hemorrhage: a critical tool in critical care. Can J Anaesth 55: 112-123.

105. Kassell NF, Sasaki T, Colohan AR, Nazar G (1985) Cerebral vasospasm following aneurysmal subarachnoid hemorrhage. Stroke 16: 562-572.

106. Bederson JB, Connolly ES Jr, Batjer HH, Dacey RG, Dion JE, et al. (2009) Guidelines for the management of aneurysmal subarachnoid hemorrhage: a statement for healthcare professionals from a special writing group of the Stroke Council, American Heart Association. Stroke 40: 994-1025.

107. Vespa PM, Nuwer MR, Juhász C, Alexander M, Nenov V, et al. (1997) Early detection of vasospasm after acute subarachnoid hemorrhage using continuous EEG ICU monitoring. Electroencephalogr Clin Neurophysiol 103: 607-615.

108. Alldredge BK, Gelb AM, Isaacs SM, Corry MD, Allen F, et al. (2001) A comparison of lorazepam, diazepam, and placebo for the treatment of out-ofhospital status epilepticus. N Engl J Med 345: 631-637.

109. McMullan J, Sasson C, Pancioli A, Silbergleit R (2010) Midazolam versus diazepam for the treatment of status epilepticus in children and young adults: a meta-analysis. Acad Emerg Med 17: 575-582.

110. Gottwald MD, Akers LC, Liu PK, Orsulak PJ, Corry MD, et al. (1999) Prehospita stability of diazepam and lorazepam. Am J Emerg Med 17: 333-337.

111. Warden CR, Frederick C (2006) Midazolam and diazepam for pediatric seizures in the prehospital setting. Prehosp Emerg Care 10: 463-467.

112. Silbergleit R, Durkalski V, Lowenstein D, Conwit R, Pancioli A, et al. (2012) Intramuscular versus intravenous therapy for prehospital status epilepticus. N Engl J Med 366: 591-600.

113. Karceski SC (2001) Expert consensus guidelines: treatment of epilepsy. Epilepsy Behav 2:A1-A50.

114. Rutecki P (1990) Anatomical, physiological, and theoretical basis for the antiepileptic effect of vagus nerve stimulation. Epilepsia 31 Suppl 2: S1-6.

115. Bailey $P$, Bremer F (1938) A sensory cortical representation of the vagus nerve with a note on the effects of low blood pressure on the cortical electrogram. $J$ Neurophysiol 1: 405-412.

116. ZANCHETTI A, WANG SC, MORUZZI G (1952) The effect of vaga afferent stimulation on the EEG pattern of the cat. Electroencephalogr Clin Neurophysiol 4: 357-361.

117. Hosain S, Nikalov B, Harden C, Li M, Fraser R, et al. (2000) Vagus nerve stimulation treatment for Lennox-Gastaut syndrome. J Child Neurol 15: 509512.

118. Labar D, Murphy J, Tecoma E (1999) Vagus nerve stimulation for medicationresistant generalized epilepsy. E04 VNS Study Group. Neurology 52: 15101512.

119. Labar D, Nikolov B, Tarver B, Fraser R (1998) Vagus nerve stimulation for symptomatic generalized epilepsy: a pilot study. Epilepsia 39: 201-205.

120. Wilder BJ (1997) Vagal nerve stimulation. In: Engel J Jr, Pedley TA, eds. Epilepsy: A Comprehensive Textbook. Philadelphia: Lippincott-Raven 13531358.

121. Karceski S (2001) Vagus nerve stimulation and Lennox-Gastaut syndrome: a review of the literature and data from the VNS patient registry. CNS Spectr 6: 766-770.

122. Benbadis SR, Tatum WO 4th (2001) Advances in the treatment of epilepsy. Am Fam Physician 64: 91-98.

123. Fisher RS, Mirski M, Krauss G (1997) Brain stimulation. In: Engel J Jr, Pedley TA, eds. Epilepsy: A Comprehensive Textbook. Philadelphia: LippincottRaven 1867-1875

124.Schwartzkroin PA, Mclntyre DC (1997) Limbic Anatomy and physiology. In: Engel J Jr, Pedley TA, eds. Epilepsy: A Comprehensive Textbook. Philadelphia: Lippincott-Raven 323-340.
125. Goldman HW, Sussman NM, Callanan M (1988) Anterior thalamic stimulation for medically refractory epilepsy, part I: implantation and stimulation. Epilepsia 29: 677.

126. Sussman NM, Goldman HW, Jackel RA (1988) Anterior thalamic stimulation in medically refractory epilepsy, part II: preliminary clinical results. Epilepsia 29: 677.

127. Fisher RS, Uematsu S, Krauss GL, Cysyk BJ, McPherson R, et al. (1992) Placebo-controlled pilot study of centromedian thalamic stimulation in treatment of intractable seizures. Epilepsia 33: 841-851.

128. Mirski MA, Rossell LA, Terry JB, Fisher RS (1997) Anticonvulsant effect of anterior thalamic high frequency electrical stimulation in the rat. Epilepsy Res 28: 89-100.

129. Fisher RS (2008) Non-Pharmacological Approach: Release of the "Stimulation of the Anterior Nucleus of the Thalamus in Epilepsy (SANTE)." Trial Results American Epilepsy Society Meeting. Seattle, WA.

130. Tellez-Zenteno JF, McLachlan RS, Parrent A, Kubu CS, Wiebe S (2006) Hippocampal electrical stimulation in mesial temporal lobe epilepsy. Neurology 66: 1490-1494.

131. Boon P, Vonck K, De Herdt V, Van Dycke A, Goethals M, et al. (2007) Deep brain stimulation in patients with refractory temporal lobe epilepsy. Epilepsia 48: $1551-1560$

132. Murro AM, Park YD, Bergey GK, Kossoff EH, Ritzl EK, et al. (2003) Multicenter study of acute responsive stimulation in patients with intractable epilepsy. Epilepsia 44: 326

133. Peters TE, Bhavaraju NC, Frei MG, Osorio I (2001) Network system for automated seizure detection and contingent delivery of therapy. J Clin Neurophysiol 18: 545-549.

134. Smith JR, Fountas KN, Murro AM, Park YD, Jenkins PD, et al. (2009) : Closed loop stimulation in the control of focal epilepsy; in Krames $\mathrm{E}$, Peckham $\mathrm{PH}$ Rezai AR (eds): Textbook of Neuromodulation. Amsterdam, Elsevier vol 2 : 657-662.

135. Smith JR, Fountas KN, Murro AM, Park YD, Jenkins PD, et al. (2010) Closedloop stimulation in the control of focal epilepsy of insular origin. Stereotact Funct Neurosurg 88: 281-287.

136. Munari C, Hoffmann D, Francione S, Kahane P, Tassi L, et al. (1994) Stereoelectroencephalography methodology: advantages and limits. Acta Neurol Scand 152: 56-67.

137. Guenot M, Isnard J, Ryvlin P (2001) Neurophysiological monitoring for epilepsy surgery: the Talairach SEEG method: stereoelectroencephalography: indications, results, complications and therapeutic applications in a series of 100 consecutive cases. Stereotact. Funct Neurosurg 77: 29-32.

138. Catenoix H, Mauguière $F$, Guénot $M$, Ryvlin $P$, Bissery A, et al. (2008) SEEG guided thermocoagulations: a palliative treatment of nonoperable partial epilepsies. Neurology 71: 1719-1726.

139. Spencer SS, Schramm J, Wyler A, O'Connor M, Orbach D, et al. (2002) Multiple subpial transection for intractable partial epilepsy: an international meta-analysis. Epilepsia 43: 141-145.

140. Reutens DC, Bye AM, Hopkins IJ, Danks A, Somerville E, et al. (1993) Corpus callosotomy for intractable epilepsy: seizure outcome and prognostic factors Epilepsia 34: 904-909.

141.Parrent AG, Lozano AM (2000) Stereotactic surgery for temporal lobe epilepsy. Can J Neurol Sci 27 Suppl 1: S79-84.

142. Cohen-Gadol AA, Stoffman MR, Spencer DD (2003) Emerging surgical and radiotherapeutic techniques for treating epilepsy. Curr Opin Neurol 16: 213219.

143. Polkey CE (2003) Alternative surgical procedures to help drug-resistant epilepsy - a review. Epileptic Disord 5: 63-75.

144. Ascher PW, Justich E, Schröttner O (1991) Interstitial thermotherapy of central brain tumors with the Nd:YAG laser under real-time monitoring by MRI. J Clin Laser Med Surg 9: 79-83.

145. Kahn T, Bettag M, Ulrich F, Schwarzmaier HJ, Schober R, et al. (1994) MRIguided laser-induced interstitial thermotherapy of cerebral neoplasms. Comput Assist Tomogr 18: 519-532.

146. Kettenbach J, Silverman SG, Hata N, Kuroda K, Saiviroonporn P, et al. (1998) 
Citation: Yeo LLL, Ong JYY, Wakerley BR, Rathakrishnan R (2012) An Update on Promising Diagnostic and Therapeutic Interventions in Epilepsy. J Neurol Neurophysiol S2:005 doi:10.4172/2155-9562.S2-005

Page 8 of 8

Monitoring and visualization techniques for MR-guided laser ablations in an open MR system. J Magn Reson Imaging 8: 933-943.

147.Bauman JA, Feoli E, Romanelli P, Doyle WK, Devinsky O, et al. (2005)
Multistage epilepsy surgery: safety, efficacy, and utility of a novel approach in pediatric extratemporal epilepsy. Neurosurgery 56: 316-334.

148. Goodman RR (2011) AES 2009 Annual Course: Reoperation for medically refractory epilepsy. Epilepsy Behav 20: 241-246.

This article was originally published in a special issue, Epilepsy: Current

Trends handled by Editor(s). Dr. Espinosa PS, Centro Internacional en

Neurociencias, USA 